\title{
Calculation of Rational Parameter \\ is Separated Monolith Stones in the Development of Fields with Complex Occurrence Natural \\ Cracks in Array
}

\author{
Gennadiy D. Pershin and Maxim S. Ulyakov* \\ Magnitogorsk State Technical University named after G.I. Nosov \\ 38 Lenin Str., Magnitogorsk, 455000, Russia
}

Received 05.03.2015, received in revised form 17.11.2015, accepted 07.12.2015

\begin{abstract}
Proposed the idea of increasing the yield of commodity blocks of rock mass by minimizing technological losses block products in the fields with a complex of natural occurrence of a separate entity, a limited system kruto- and dipping fractures ; increase productivity and reduce the cost of separation of monoliths from the array through the study of optimal height quarry face. The method of calculation of rational technological parameters of the combined method of preparation for the seizure of high stone block in the fields with complex geological conditions of mineral deposits on the basis of a two-stage scheme vysokoustupnoy mining array where the first stage is separated monolith using wire saw, and the second - on the overturned jobsite monolith blocks cut in trade with machines and stitch drilling.
\end{abstract}

Keywords: Output units , fracturing array, a high ledge, high stone monolith, trade blocks.

DOI: 10.17516/1999-494X-2015-8-8-1032-1039.

\section{Методика расчета рациональных параметров \\ отделяемых монолитов камня \\ при разработке месторождений}

со сложным залеганием природных трещин в массиве

\author{
Г.Д. Першин, М.С. Уляков \\ Магнитогорский государственный технический университет \\ им. Г.И. Носова \\ Россия, 455000, Магнитогорск, Ленина, 38
}

Предложена идея увеличения выхода товарных блоков из горного массива путем минимизации технологических потерь блочной продукции на месторождениях со сложным залеганием

(C) Siberian Federal University. All rights reserved

* Corresponding author E-mail address: maxim-atlet@yandex.ru 
природных отдельностей, ограниченных системами круто- и пологопадающих трещин, повышения производительности и снижения себестоимости отделения монолитов от массива за счет обоснования оптимальной высоты добычного уступа. Разработана методика расчета рациональных технологических параметров комбинированного способа подготовки к выемке блочного высокопрочного камня на месторождениях со сложными горно-геологическими условиями залегания полезного ископаемого на основе высокоуступной двухстадийной схемь отработки массива, когда на первой стадии отделяется монолит с помощью канатной пиль, а на второй - опрокинутый на рабочую площадку монолит раздельввается на товарные блоки с использованием станков строчечного бурения.

Ключевые слова: выход блоков, трещиноватость массива, высокий уступ, высокопрочный камень, монолит, товарные блоки.

\section{Введение}

Трещиноватостью и природной блочностью массива определяются возможность и экономическая целесообразность разработки месторождений облицовочного камня, поэтому горногеометрический анализ структуры массива не только представляет теоретический интерес, но и имеет важное практическое значение. Под структурой массива понимается геометрическое множество его монолитных частей, образованных в результате развития в массиве природной трещиноватости. Природный структурный блок, ограниченный трещинами, имеет форму прямой или наклонной призмы. На форму природного блока оказывают влияние геометрические характеристики залегания трещин в массиве - азимут простирания и угол падения, а на его объем - межтрещинные расстояния основных систем трещин. Таким образом, структура горного массива может быть описана как параметрами природной трещиноватости, так и параметрами природной блочности, которые в совокупности и определяют теоретический выход товарных блоков из массива. Фактический выход блоков при добыче существенно отличается от теоретического (предельно возможного) уровня, в связи с чем процесс добычи облицовочного камня является многоотходным производством.

Причина невысокого использования потенциала месторождений облицовочного камня состоит в недостаточном соответствии применяемой технологии добычи блоков структурным особенностям разрабатываемого породного массива [1-4]. Процентное содержание различных по объему природных блоков в массиве, а также их форма обусловливают экономическую целесообразность применения одностадийной или двухстадийной схем добычи камня. Необходимость применения двухстадийной технологии добычи обусловлена сложным залеганием природных трещин на месторождении, когда природный блок, слагающий массив, образован несколькими системами крутопадающих трещин и системой первично-пластовых (пологопадающих) трещин. При этом, как показывает опыт, двухстадийная технология особенно эффективна при разработке месторождений со слаботрещиноватой толщей горных пород.

\section{Основная часть}

В настоящее время по двухстадийной схеме отрабатывается более $90 \%$ месторождений группы мраморов, и, как правило, это единственный путь существенного повышения коэффициента выхода товарных блоков. Мраморный карьер Коелгинского месторождения (Челябинская область) и работы с 1997 г. в течение ряда лет по двухстадийной высокоуступной техно- 
логии с применением канатных пил (КП), по сравнению с двадцатилетним периодом работы по одностадийной схеме с применением баровых камнерезных машин, добился повышения выхода товарной продукции в среднем на 65 \% с повышением ее блочности за счет увеличения средневзвешенного объема блока на 75 \%. При этом рост выхода товарных блоков был получен за счет снижения технологических потерь.

Применение современной высокоуступной двухстадийной технологии добычи мраморных блоков стало возможным с появлением и использованием в карьерах КП, позволяющих в широком диапазоне изменять линейные параметры отделяемых от массива монолитов камня. Так как природная блочность массива существует как заданность месторождения, то влиять на выход товарных блоков остается только линейными параметрами отделяемых монолитов. В связи с чем был разработан ряд методик расчета и выбора рациональных параметров отделяемых монолитов в зависимости от природной трещиноватости массива [5].

Породные массивы группы гранитов, как правило, разбиты тремя системами развитых, практически ортогональных друг к другу трещин с различными межтрещинными расстояниями. Первую систему образуют пластовые трещины, имеющие горизонтальное либо слабонаклонное залегание (угол падения составляет 5-15 град). Ко второй и третьей системам относятся продольные и поперечные трещины, имеющие почти вертикальное падение. На долю продольных и поперечных трещин приходится 40-50 и 25-30 \% от общего числа трещин соответственно.

При этом могут проявляться и диагональные трещины под углом падения $\approx 45$ град. Неортогональность плоскостей продольных и поперечных трещин может достигать 15 град, что позволяет выкалывать из массива блоки, имеющие форму параллелепипеда. Так как мощность горизонтальных пластов от глубины разработки изменяется в широком диапазоне от нескольких сантиметров до нескольких метров, то отработку породного массива на его продуктивной толще осуществляют горизонтальными слоями. При этом выемка пород возможна продольными, поперечными и диагональными заходками в зависимости от расстояния между смежными вертикальными трещинами. На пластовых месторождениях отделение блоков от массива осуществляют, как правило, по одностадийной схеме, которая предусматривает получение готовой продукции (товарных блоков) сразу после отделения объема камня стандартных размеров и прямоугольной формы.

При работе горизонтальными слоями мощность отрабатываемого слоя, как правило, соответствует высоте уступа (подуступа), т.е. высоте отделяемого блока. С повышением толщи горизонтальных слоев по мере понижения отработки находит применение и двухстадийная схема, когда готовую продукцию получают с помощью дополнительных операций уже после отделения крупноразмерных блоков - монолитов.

В качестве примера перехода с одностадийной на двухстадийную схему добычи блоков высокопрочного камня можно привести Мансуровский гранитный карьер (Республика Башкортостан). Причиной перехода явился низкий выход товарных блоков, отделяемых шпуровым способом с применением механических клиньев, с нарастанием мощности пластов.

У механических (либо гидро-) клиньев распорное усилие локализовано в верхней части шпура. Поэтому с увеличением мощности пласта (уступа) наблюдается искривление трещины отрыва от заданного направления. Отклонение плоскости отрыва от намеченной контурной 
плоскости увеличивает технологические потери товарных блоков, что снижает коэффициент их выхода. Внедрение на Мансуровском гранитном карьере двухстадийной схемы с отделением на первом этапе крупных монолитов шпуровым способом с применением в теплый и переходный периоды (до минус $10{ }^{\circ} \mathrm{C}$ ) года в качестве распорных средств невзврывчатых разрушающих смесей (НPC) повысило коэффициент выхода блоков товарной кондиции от 20 до 50 \% в зависимости от участка карьера. Высота уступа по данной технологии устанавливалась в пределах 3 м и включала один, два либо три пласта в зависимости от их мощности.

Пластовое залегание пород группы гранитов с практически горизонтальными слоями дает возможность вести добычу блоков с выходом до 75 \% и более при невысоких трудозатратах. Однако такое благоприятное для камнедобычи залегание - это лишь частный случай генетической природы трещин в массиве. Более общим случаем является трансформация горизонтальных (слабонаклонных) трещин в пологопадающие, а вертикальных поперечных и продольных трещин - в крутопадающие, при этом количество крутопадающих систем может быть более двух. Выход блоков на таких месторождениях составляет 10-60 \%, что и служит главной причиной дефицита блочной продукции из высокопрочного облицовочного камня.

В последние годы в мировой индустрии камня наметилась стабильная тенденция применения КП на гранитных карьерах со сложным залеганием в массиве природных трещин. Основанием стал многолетний практический опыт и положительные результаты применения КП на мраморных карьерах. Более высокий удельный расход дорогостоящего гибкого алмазного инструмента на породах типа гранит по сравнению с породами средней прочности являлся сдерживающим фактором применения данного камнерезного оборудования при добыче гранитных блоков. Однако по мере совершенствования технологии и техники производства алмазно-канатного инструмента цена его снижалась, а применение на карьерах высокопрочного камня добычного оборудования с гибким режущим инструментом расширялось. Технология ведения добычных работ на гранитных карьерах полностью соответствует мраморным карьерам, т.е. применяется двухстадийная схема с отделением монолита от массива на первом этапе и разделкой на блоки опрокинутого монолита на рабочую площадку - на втором. При этом главной целью двухстадийной технологии также остается обеспечение повышения выхода товарных блоков в условиях сложного залегания природных трещин в массиве за счет обоснованного выбора линейных размеров отделяемого монолита.

Данную чисто геометрическую задачу будем решать при тех же упрощениях и допущениях, принятых в работе [6]. Принимаем, что природный блок ограничивается плоскостями трех почти взаимно ортогональных и наиболее развитых в массиве систем трещин, к которым относятся система пологопадающих и две системы крутопадающих трещин. Так как в первую очередь определяются высота и длина монолита, то фронтальную (продольную) плоскость монолита располагаем так, чтобы следы первой основной (пологопадающей) системы трещин и второй основной (крутопадающей) системы на фронтальную плоскость представляли собой линии падения данных трещин. В таком случае вторая система крутопадающих трещин будет располагаться практически параллельно фронтальной плоскости, которая в этом случае примет положение, ортогональное азимуту простирания первой основной системы трещин.

Полученная таким образом картограмма трещиноватости фронтальной плоскости монолита является проекциями природных отдельностей, ограниченных плоскостями отделения 
монолита от массива. На картограмме выстраиваются прямоугольники, одна из сторон которых совпадает с направлением системы трещин, имеющей минимальное межтрещинное расстояние, т.е. максимальное развитие в массиве. Площадки других геометрических фигур, как правило, треугольной формы, помноженные на ширину монолита, будут выражать технологические потери блочной продукции, так как согласно ГОСТ 9479-2011 «Блоки из горных пород для производства облицовочных, архитектурно-строительных, мемориальных и других изделий» за технологические потери принимаются все объемы камня, составляющие монолит, которые не вписываются в форму прямоугольного параллелепипеда или близкую к нему.

Продуктивность принятой в работе [6] расчетной схемы заключается в том, что высота и длина монолита выражаются в целочисленных значениях количеством пологопадающих и крутопадающих отдельностей. Так, за высоту монолита принимается расстояние, кратное числу пологопадающих отдельностей, а длина монолита определяется числом, кратным круто- и пологопадающим отдельностям в пределах фронтальной плоскости монолита. Предложенная методика расчета позволила в простом виде получить геометрические уравнения, в параметрическом виде связывающие искомые линейные параметры монолита от горно-геометрических параметров трещиноватости массива [7-12]:

$$
\begin{aligned}
& H_{y}=H_{M}=n_{n} \cdot l_{n} \cdot \sin \delta_{\kappa} / \sin \gamma \\
& L_{M}=n_{\kappa} \cdot \frac{l_{\kappa}}{\sin \delta_{K}}+n_{n} \cdot \frac{l_{n}}{\sin \gamma} \cdot \cos \delta_{\kappa} \\
& k_{m \cdot n}=\frac{\left[\frac{\left(n_{n} \cdot l_{n}\right)^{2} \cdot \sin \delta \cdot \cos \delta_{K}}{(\sin \gamma)^{2}}+l_{\kappa}^{2} \cdot n_{\kappa} \cdot \operatorname{ctg} \delta_{\kappa}+n_{n} \cdot n_{\kappa} \cdot l_{\kappa}^{2} \cdot \operatorname{ctg} \gamma\right]}{\left(H_{M} \cdot L_{M}\right)},
\end{aligned}
$$

где $n_{\kappa}$ и $n_{n}$ - количество отдельностей систем круто- и пологопадающих трещин массива, шт.; $\delta_{k}, \delta_{n}$ - углы падения круто- и пологопадающих систем трещин, град; $\gamma$ - угол между круто- и пологопадающими системами трещин, град; $l_{k}$ и $l_{n}$ - расстояние между круто- и пологопадающими системами трещин, м; $k_{m, n}$ - коэффициент относительных технологических потерь блочной продукции.

Суммарные относительные технологические потери блочной продукции предложено записать и как функцию высоты уступа (1). В результате выражение (3) примет следующий вид:

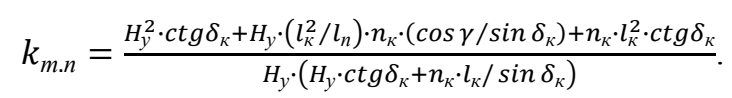

Нахождение экстремумов технологических потерь по условию

$$
\partial k_{m . n} / \partial H_{y}=0
$$

дает зависимость для расчета оптимальной (с минимальными технологическими потерями) высоты уступа:

$$
\begin{gathered}
H_{y}^{o n}=\frac{l_{K^{*}} \cdot\left[\cos \delta_{K}+\sqrt{\left(\cos \delta_{K}\right)^{2}+n_{K} \cdot\left(1-\left(l_{K} / l_{n}\right) \cdot \cos \gamma\right)}\right]}{\left(1-\left(l_{K} / l_{n}\right) \cdot \cos \gamma\right)} \\
-1036-
\end{gathered}
$$


Определение оптимальной высоты уступа позволяет найти из (2) и длину монолита как рациональную величину:

$$
L_{M}=n_{\kappa} \cdot \frac{l_{\kappa}}{\sin \delta_{\kappa}}+H_{y}^{o n} \cdot \operatorname{ctg} \delta_{\kappa}
$$

Как видим из полученных выражений (6) и (7), каждому целочисленному значению $n_{\kappa}$ при заданной характеристике трещиноватости массива соответствует оптимальное значение высоты уступа и рациональная величина длины монолита, которым отвечает условие минимальных технологических потерь блочной продукции, т.е. условие максимального выхода блоков (рис. 1).

В качестве критерия определения величины $n_{\kappa}$ принято относительное снижение технологических потерь блочной продукции (рис. 2). По наибольшему значению данного показателя с учетом рациональных размеров рабочей площадки и возможности опрокидывания на нее монолита для горно-геологических условий Юго-Восточного участка Нижне-Санарского месторождения гранодиорита находим $n_{\kappa}=3$ либо $n_{\kappa}=4$.

Для оценки влияния режима работы КП на себестоимость пиления необходимо еще определить рациональную ширину монолита $(B)$. Она находится из условия наибольшего выхода блоков из монолита и возможности его опрокидывания на рабочую площадку. Применительно

a

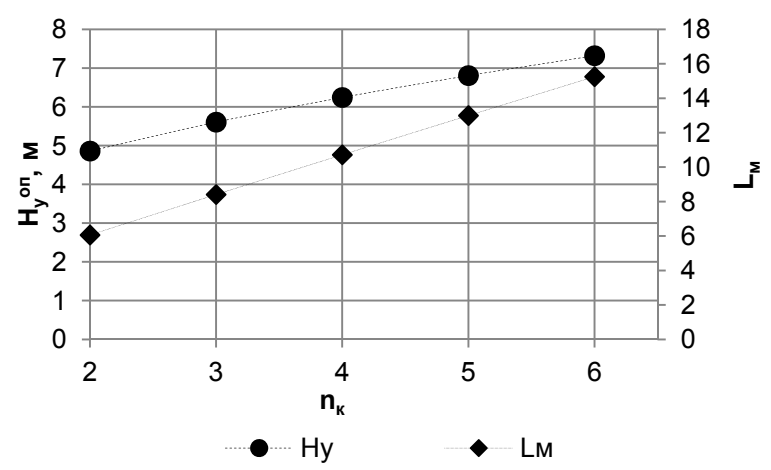

6

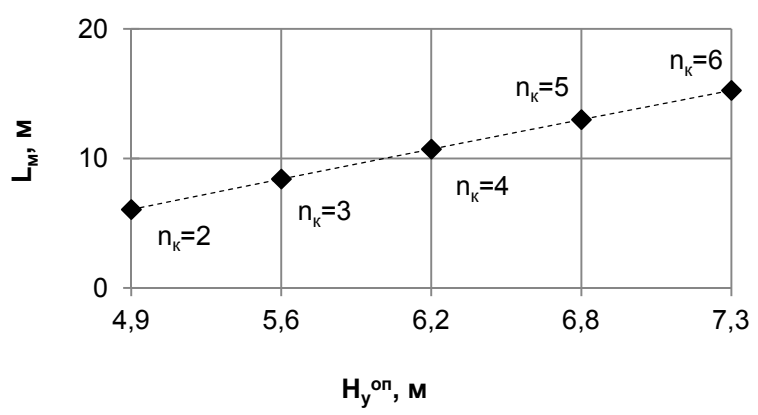

Рис. 1. Зависимость: а - оптимальной высоты уступа и длины монолита от количества в нем крутопадающих отдельностей; б - длины монолита от оптимальной высоты уступа и количества в нем крутопадающих отдельностей для Юго-Восточного участка Нижне-Санарского месторождения гранодиорита $\left(\delta_{\kappa}=68^{\circ}, \gamma=65^{\circ}, l_{\kappa}=1,9 \mathrm{M}, l_{n}=2 \mathrm{м}\right)$ 


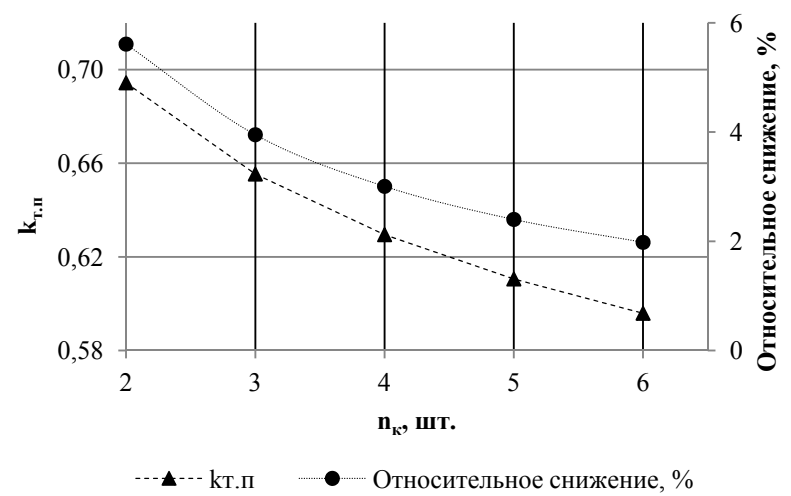

Рис. 2. Зависимость коэффициента относительных технологических потерь блочной продукции $\left(k_{m . n}\right)$ и относительного снижения его величины (относительное снижение, \%) от количества отдельностей крутопадающих систем трещин массива $\left(n_{\kappa}\right.$, шт.)

к горно-геологическим характеристикам трещиноватости Юго-Восточного участка НижнеСанарского месторождения гранодиорита $\left(\delta_{\kappa}=68^{\circ}, \gamma=65^{\circ}, l_{\kappa}=1,9\right.$ м, $l_{n}=2$ м) по разработанной методике были рассчитаны рациональные размеры отделяемого монолита: для $n_{\kappa}=3-H_{y}^{o n}=5,6 \mathrm{M}$, $L_{\mu}=8,4 \mathrm{M}, B_{\mu}=1,7 \mathrm{м}$; для $n_{\kappa}=4-H_{y}^{o n}=6,2 \mathrm{M}, L_{\mu}=10,7 \mathrm{M}, B_{\mu}=1,7 \mathrm{M}$.

\section{Выводы}

1. Совершенствование процесса подготовки блоков к выемке на месторождениях с системами круто- и пологопадающих трещин осуществляется за счет использования комбинированного способа по двухстадийной высокоуступной схеме, когда на первой стадии от горного массива отделяется монолит с помощью КП, а на второй стадии, после завалки монолита на рабочую площадку, осуществляется его разделка на товарные блоки с использованием станков строчечного бурения.

2. Получена зависимость величины технологических потерь блочной продукции от высоты уступа и геометрических характеристик природных трещин горного массива. Путем минимизации данной зависимости как условия, обеспечивающего повышение выхода блоков, определена оптимальная высота уступа, в соответствии с которой находят высоту и длину монолита.

3. Согласно разработанной методике для горно-геологических условий Юго-Восточного участка Нижне-Санарского месторождения гранодиоритов $\left(\delta_{k}=68^{\circ}, \gamma=65^{\circ}, l_{\kappa}=1,9\right.$ м, $l_{n}=2$ м) рассчитаны рациональные линейные параметры отделяемых монолитов:

- для трех отдельностей системы крутопадающих трещин массива $-H_{s}=5,6 \mathrm{~m} ; L_{s}=8,4 \mathrm{~m}$; $B_{M}=1,7 \mathrm{M}$;

- для четырех отдельностей системы крутопадающих трещин массива $-H_{\mu}=6,2 \mathrm{м} ; L_{\mu}=10,7$ $\mathrm{M} ; B_{M}=1,7 \mathrm{м}$. 


\section{Список литературы}

[1] Першин Г.Д., Уляков М.С. Физико-технические проблемы разработки полезных ископаемых, 2014, 2, 125-135 [Pershin G.D., Uliakov M.S. Journal of Mining Sciences, 2014, 2, $125-135]$

[2] Першин Г.Д., Уляков М.С. Вест. Магнитогор. гос. тех. ун-та им. Г.И. Носова, 2014, 4(48), 14-21 [Pershin G.D., Uliakov M.S. [Herald of Magnitogorsk State Tech. Univ. named after G.I. Nosov], 2014, 4 (48), 14-21]

[3] Першин Г.Д., Уляков М.С. Известия вузов. Горный журнал, 2014, 7, 10-18 [Pershin G.D., Uliakov M.S. Proceedings of the universities. Mining Journal, 2014, 7, 10-18]

[4] Першин Г.Д., Уляков М.С. Известия вузов. Горный журнал, 2014, 8, 22-30 [Pershin G.D., Uliakov M.S. Proceedings of the universities. Mining Journal, 2014, 8, 22-30]

[5] Косолапов А.И., Невежин А.Ю. Добыча, обработка и применение природного камня: сб. науч. трудов. Магнитогорск: МГТУ, 2003, 119-128 [Kosolapov A.I., Nevezhin A.Iu. Mining, processing and application of natural stone: sat. scientific works, Magnitogorsk State Technical University named after G.I. Nosov, 2003, 119-128]

[6] Першин Г.Д., Пшеничная Е.Г., Уляков М.С. Добыча, обработка и применение природного камня: сб. науч. тр. Магнитогорск: МГТУ, 2013, 4-12 [Pershin G.D., Pshenichnaia G.D., Uliakov M.S. Mining, processing and application of natural stone: sat. scientific works, Magnitogorsk State Technical University named after G.I. Nosov, 2013, 4-12]

[7] Вагин В.С., Филатов А.М., Курочкин А.И. Вест. Магнитогор. гос. тех. ун-та им. Г.И. Носова, 2014, 3(47), $25-29$ [Vagin, V.S., Filatov A.M., Kurochkin A.I. Herald of Magnitogorsk State Tech. Univ. named after G.I. Nosov], 2014, 3(47), 25-29]

[8] Пащенко К.Г., Бахматов Ю.Ф., Кальченко А.А. и др. Современные наукоемкие технологии, 2015, 2,107-111 [Pashchenko K.G., Bakhmatov Iu. F., Kalchenko A.A. et. al. Modern High Technologies, 2015, 2, 107-111]

[9] Жиркин Ю.В., Мироненков Е.И., Султанов Н.Л. и др. Современные наукоемкие технологии, 2015, 2, 52-57 [Zhirkin Iu.V., Vironenkov E.I., Sultanov N.L. et. al. Modern High Technologies, 2015, 2, 52-57]

[10] Бахматов Ю.Ф., Пащенко К.Г., Кальченко А.А. и др. Металлург, 2014, 4, 88-91 [Bakhmatov Iu. F., Pashchenko K.G., Kalchenko A.A. et. al. Metallurg, 2014, 4, 88-91]

[11] Левицький В.Г., Соболевський Р.В. Восточно-Европейский журнал передовых технологий, 2014, 3(3/69), 48-52 [Levitskii V.G., Sobolevskii R.V. East European Journal of advanced technologies, 2014, 3(3/69), 48-52]

[12] Айбашев Д.М., Кольга А.Д., Хажиев А.А. Вестник развития науки и образования, 2014, 3, 163-166 [Aibashev D.M., Kolga A.D., Khazhiev A.A. Bulletin of Science and Education Development, 2014, 3, 163-166] 